\title{
Correction to: Clinical Guide to Early Interventions for Children with Autism
}

Giacomo Vivanti, Kristen Bottema-Beutel, and Lauren Turner-Brown

\section{Correction to:}

Chapter 3 and 4 in: G. Vivanti et al. (eds.), Clinical Guide to Early Interventions for Children with Autism, Best Practices in Child and Adolescent Behavioral Health Care, https://doi.org/10.1007/978-3-030-41160-2

Mary Kate Frisch provided her valuable contribution to chapter 4 "Understanding and Addressing Restricted and Repetitive Behaviors in Children with Autism" of this book. However, the author's name was inadvertently added to chapter 3 instead of chapter 4 . This error has been corrected in this version of the book.

The updated online version of this chapter can be found at https://doi.org/10.1007/978-3-030-41160-2_3

https://doi.org/10.1007/978-3-030-41160-2_4 